CIRJE-F-783

\title{
Life-Cycle Labor Search with Stochastic Match Quality
}

\author{
Julen Esteban-Pretel \\ Junichi Fujimoto \\ University of Tokyo
}

National Graduate Institute for Policy Studies

January 2011

CIRJE Discussion Papers can be downloaded without charge from:

$\underline{\text { http://www.cirje.e.u-tokyo.ac.jp/research/03research02dp.html }}$

Discussion Papers are a series of manuscripts in their draft form. They are not intended for circulation or distribution except as indicated by the author. For that reason Discussion Papers may not be reproduced or distributed without the written consent of the author. 


\title{
Life-Cycle Labor Search with Stochastic Match Quality*
}

\author{
Julen Esteban-Pretel ${ }^{\dagger}$ \\ National Graduate Institute for Policy Studies
}

\author{
Junichi Fujimoto $\ddagger$ \\ University of Tokyo
}

January 8, 2011

\begin{abstract}
Unemployment, job finding, and job separation rates exhibit patterns of decline as worker age increases in the U.S. We build and numerically simulate a search and matching model of the labor market that incorporates a life-cycle structure to account for these empirical facts. The model features random match quality, which, with positive probability, is not revealed until production takes place. We show that the model, calibrated to U.S. data, is able to reproduce the empirical patterns of unemployment and job transition rates over the entire life-cycle. Both decreasing distance to retirement as a worker ages, and ex ante unknown match quality, are essential in delivering these results. We then explore, both analytically and numerically, the efficiency implications of the model.

Keywords: Search and Matching; Life-Cycle; Overlapping Generation; Match Quality

JEL Classification: E24, J63, J64
\end{abstract}

${ }^{*}$ We thank James Albrecht, Hirokatsu Asano, Toni Braun, Hidehiko Ichimura, Ryoichi Imai, Daiji Kawaguchi, Noritaka Kudoh, Ryo Nakajima, Hideo Owan, Makoto Saito, Etsuro Shioji, Katsuya Takii, Ryuichi Tanaka, Susan Vroman and seminar participants at Hitotsubashi University, University of Tokyo Macrofinance Workshop, The Second Search Theory Conference at Osaka University, the RIETI Empirical Analysis of Japan's Labor Market Meetings, and Tokyo Macro Workshop for comments and suggestions. We respectively acknowledge financial support for this project by the Japanese Ministry of Education through the Grant-in-Aid for Young Researchers. All errors are our own.

${ }^{\dagger}$ National Graduate Institute for Policy Studies (GRIPS). 7-22-1 Roppongi, Minato-ku, Tokyo 106-8677, Japan. E-mail: julen@grips.ac.jp; Tel: +81-3-6439-6000 Fax: +81-3-6439-6010.

${ }^{\ddagger}$ Faculty of Economics, University of Tokyo, 7-3-1 Hongo, Bunkyo-ku, Tokyo 113-0033, Japan. Email: junichif@e.u-tokyo.ac.jp; Tel: +81-3-5841-5524; Fax: +81-3-5841-8294. 


\section{Introduction}

Labor market experiences vary greatly for workers of different ages. Disaggregated U.S. data shows that the unemployment rate, as well as the probabilities of finding and losing a job, all decrease with age. Traditional search and matching literature, which has become a standard theory of equilibrium unemployment, has not placed much emphasis on explaining the life-cycle patterns of labor market variables. The ability to explain these basic agedependent labor market facts is an important first step for analyzing various important policy issues, such as youth unemployment.

The main objective of this paper is to build a model capable of quantitatively accounting for the declining patterns in three variables, unemployment, job separation, and job finding rates, over the worker life-cycle, as observed in U.S. data. More precisely, our model attempts to account for the following facts. ${ }^{1}$ First, the unemployment rate monotonically decreases with age, from 16 percent for the youngest five-year age group, to less than 4 percent for workers in the age group about to retire. Second, the quarterly job separation rate also monotonically declines as age advances, from 8 to 2 percent, for the youngest and oldest age groups, respectively. And third, the quarterly job finding rate drops monotonically with age, from 73 to 61 percent.

We develop a search and matching model of the labor market in the style of Cheron, Hairault, and Langot (2008) and Hahn (2009), which depart from the standard framework by assuming finite lives for individuals. This life-cycle nature of the model allows us to analyze the age-dependent facts of interest. As in these two papers, our model features nonsegmented labor markets by age, and as in Cheron, Hairault, and Langot (2008), it delivers endogenous job destruction. While the above-mentioned studies do a good job accounting for the inverted U-shape of the employment-to-population ratio across ages, they do not attempt to quantitatively explain the life-cycle patterns of the three main variables of interest. For instance, Hahn (2009) assumes exogenous separations, hence is unable to obtain the decline in separation rate as workers age. Similarly, in Cheron, Hairault, and Langot (2008), there is a direct negative relationship between the job finding and separation rates of workers of different ages, which contradicts the decline with age observed in the data of both these variables. We build on these two papers by incorporating an additional feature in the model to account for all three facts. That is, we assume that matches differ in quality, which is randomly determined at the beginning of the employment relationship, remains unchanged over its duration, and with positive probability, is not revealed until

\footnotetext{
${ }^{1}$ These facts are averages from 1976 to 2005 of the variables of interest, calculated using the Current Population Survey.
} 
production starts.

We calibrate the model to U.S. data, and show through numerical simulations that the model is able to successfully reproduce the three empirical facts, namely, decline over the life-cycle in job finding rate, job separation rate, and unemployment rate. The key mechanisms behind our results are endogenous job destruction and the revelation of random match quality, whose intuition can be explained as follows.

First, as in Cheron, Hairault, and Langot (2008), our model is able to generate a declining job finding rate as individuals age, despite featuring a single labor market, which implies that all unemployed workers find a firm with the same probability. This results from the horizon effect: the closer distance to retirement for older workers reduces the number of periods remaining to profit from the match, and it lowers the overall surplus. This makes the firm more selective in hiring older workers, such that a larger fraction of matches for these workers is immediately destroyed without resulting in an employment relationship, hence reducing the job finding rate. However, when the only mechanism at work is the horizon effect, as in Cheron, Hairault, and Langot (2008), this same mechanism generates counterfactually lower separation rates for younger workers.

In our model, the inclusion of random match quality breaks this link and delivers declining job separation rates over the life-cycle. With positive probability, match quality is unknown when the match is formed, and is revealed in the early stages of the employment relationship, at which time many low-quality matches are destroyed. Since every individual is unemployed at the beginning of their working life, the proportion of workers in such newly formed matches is greater for younger workers, which produces their higher separation rates. In addition, the opportunity cost of staying in a low-quality match is higher for younger workers who have longer careers ahead of them; this also increases their separation rate.

Finally, our model matches the empirically observed declining unemployment rates across ages. This is because, in our model, young workers enter the labor market without a job and face higher separation rates, which turns out to dominate the effect of their higher job finding rates.

We also study the efficiency implications of the model. We find that, similarly to the existing literature, the market equilibrium is not efficient, even when the Hosios (1990) condition is imposed. The intuition behind this finding is that by assuming a single market, an externality arises where unemployed workers of different ages, who would have new matches with different surpluses, are pooled together. This intergenerational externality is not internalized by the Hosios condition, hence the inefficiency persists. We find, however, that numerically the differences between the market and planner allocations are small, 
except for the job finding rate of workers about to retire. We then explore government policies that achieve the efficient allocation, and find that a combination of hiring subsidies and age-dependent firing taxes accomplishes this goal.

Our paper is related to two strands of literatures. First, it builds on work that embeds an overlapping generations structure into labor search and matching models. A pioneer in this body of literature is Pissarides (1992), which uses a random matching model where workers live for two periods, to explain the effects of skill loss on the persistence of unemployment over the business cycle. A similar framework is used in Arcidiacono (2003) to study racial discrimination in the U.S. labor market. Recent models in this area allow much more general specifications where workers live for many periods (Cheron, Hairault, and Langot (2008)), or for a constant duration in continuous time (Hahn (2009)), which enables more realistic analyses of the life-cycle empirical facts, such as the inverted U-shape of the employment rate. Menzio, Telyukova, and Visschers (2010) develops a life-cycle directed search model and attempts to match key life-cycle features of labor market variables, but this work differ from ours in adopting long-term contracts and allowing the labor market to be segmented by age, through the posting of contracts that specify applicant age.

Second, our paper relates to the literature on match quality and learning. This was first investigated in Jovanovic (1979), in which a gradual learning of the match quality leads to a decline in separation probability and a rise in the average wage as tenure increases. Jovanovic (1984) extends this framework to a one-sided search model of the labor market. More recently, Pries and Rogerson (2005) embeds the learning of match quality into a search and matching model, in order to quantitatively explain the differences in worker turnover between Europe and the U.S. To the best of our knowledge, our paper is the first to combine these two literatures to analyze the effects of match quality on worker flows over the worker life-cycle.

The remainder of this paper is organized as follows. Section 2 explains the main empirical facts that the paper tries to account for. Section 3 develops the model, and Section 4 displays the numerical results. Section 5 discusses issues related to efficiency of the model. Finally, Section 6 summarizes the main conclusions of the paper.

\section{Empirical Life-Cycle Patterns}

In this section, we examine the behavior of three of the main variables in the U.S. labor market, disaggregated by age. In particular, Figure 1 shows the average for the period 1976-2005 of the unemployment rate, and the quarterly job separation and finding rates 
for five-year age groups. ${ }^{2}$ Overall, these figures show that the labor market experience of workers at different ages is far from homogeneous. All these rates decline with age, indicating that there is a marked age component to worker flows and the resulting unemployment rates. Let us now analyze the data in more detail.

We observe in Figure 1a that the unemployment rate is decreasing in age. The average unemployment rate in the U.S. economy over this period for workers between 16 and 65 years of age is 6.2 percent. Very young workers, aged 16 to 20 , have suffered from an over 16 percent unemployment rate in the past 30 years. The fraction of unemployed workers declines sharply as age increases, and seems to stabilize around 4 percent in the age groups between 36 to 65 .

Figure $1 \mathrm{~b}$ displays the quarterly job separation rate. We observe that the probability of a worker moving from employment to unemployment also declines with age. The average for all ages for the sample period is 3.2 percent and, as in the case of the unemployment rate, it declines sharply during the first years of participation in the labor market. Workers aged 16 to 20 flow from employment into unemployment at an average quarterly rate of almost 8 percent, but after the age of 30 the job separation rate declines more slowly and employed workers seem to lose their job at a rate of around 2 percent per quarter.

The behavior of the job finding rate is described in Figure 1c. The average probability, for all age groups, of a worker transitioning from unemployment to employment in a given quarter is 67.1 percent. The job finding rate is almost the same for workers aged 16 to 20 and 21 to 25 , but after the age of 25 it decreases with age.

\section{Model}

We now build a search and matching model of the labor market to try to account for the three facts discussed above. Since we are interested in studying differences in labor market experiences by age, however, we diverge from the traditional assumption of infinitely lived individuals, and assume that agents live only for a finite number of periods. Our model also

\footnotetext{
${ }^{2}$ The data displayed in these figures are constructed using the Current Population Survey data available at the NBER website: http://www.nber.org/data/cps_basic.html, and the "Gross Worker Flows" methodology and codes available at Robert Shimer's website: http://sites.google.com/site/robertshimer/research/flows. There is one difference, however, from the methodology of Shimer. Shimer calculates the monthly job finding and separation rates as $J F R_{t}=\frac{U E_{t}}{U E_{t}+U I_{t}+U U_{t}}$ and $J S R_{t}=\frac{E U_{t}}{E U_{t}+E I_{t}+E E_{t}}$, where $X Y_{t}$ for $X, Y \in\{E, U, I\}$, is the number of workers whose employment state, either employed $(E)$, unemployed $(U)$, or inactive $(I)$, is $X$ in month $t-1$ and $Y$ in $t$. Since there is no inactivity state in our model, we define these rates as $J F R_{t}=\frac{U E_{t}}{U E_{t}+U U_{t}}$ and $J S R_{t}=\frac{E U_{t}}{E U_{t}+E E_{t}}$. The quarterly job finding and separation rates shown here are the probabilities that a worker moves from unemployment to employment, and vice versa, in any three-month period, and are therefore computed from these monthly transition rates by considering all possible transition paths between the two states, $E$ and $U$.
} 
departs from the text-book version of such models in including the feature that matches differ in quality; there is a certain probability that such difference in quality is revealed at the start of the matches. We show that this uncertainty in match quality is important to account for some of the previously discussed labor market facts. Let us now examine the model in greater detail.

\subsection{Environment}

Time is discrete and goes to infinity. There are two types of agent in the economy: firms and workers. Both firms and workers are risk neutral. Firms are ex ante homogeneous, and post vacancies in the labor market. If matched with a worker, the firm decides whether to start an employment relationship with the worker and produce output. Employment relationships are between one firm and one worker. Workers live for $\mathrm{T}$ periods. ${ }^{3}$ They search for jobs, and if matched with a firm, decide whether to start employment. There are a continuum of workers of each age, and the total mass of workers for each age group is normalized to 1 .

We assume that the labor market is not segmented by age, such that unemployed workers of all ages compete for the same vacancies. Workers and firms are matched according to a constant returns to scale matching function, $m(u, v)=v q(\theta)$, where $u$ and $v$ are, respectively, the number of unemployed workers and vacancies, and $\theta \equiv \frac{v}{u}$ is market tightness. The matching function implies that $q(\theta)$ is the vacancy filling rate for a vacant firm, and that $\theta q(\theta)$ is the job finding rate for an unemployed worker.

A match between a firm and a worker differs along several dimensions. The first difference is the overall quality of the match. Each firm-worker pair has a specific match quality, $\mu \in\left\{\mu_{1}, \mu_{2}, \ldots, \mu_{N}\right\}$, which is constant throughout the duration of the match. The actual level of $\mu$ is revealed at the moment of matching with probability $R_{a}$, which may depend on age. With probability $1-R_{a}$, the match quality is unknown at the moment of the match, and is revealed only after one period of employment and after paying cost c. ${ }^{4}$ The distribution of match quality is independent of age, such that $\operatorname{Pr}\left(\mu=\mu_{n}\right)=\pi_{n}$, where $\sum_{n=1}^{N} \pi_{n}=1$. Matches also differ in their productivity. The productivity of a job, $\epsilon$, is idiosyncratic to each match and is i.i.d. over time and across matches. It is drawn every period, including the initial period of the match, from a distribution $G$ with support $\left[\epsilon_{\min }, \epsilon_{\max }\right]$. The output of a productive match is the product of these two components,

\footnotetext{
${ }^{3}$ The distinction between death and retirement is irrelevant for the model, so we can also interpret that workers stay in the labor market for $\mathrm{T}$ periods.

${ }^{4}$ Since idiosyncratic productivity $\epsilon$ and output $\mu \epsilon$ are observed without noise, $\mu$ is revealed after one period of employment. It is possible to introduce more complicated scenarios of learning, but we adopt this simple learning process since our main emphasis is not on the theoretical aspects of learning.
} 
i.e. $\mu \epsilon$.

Destruction of matches occurs in three forms. Matches are destroyed exogenously at a rate $\delta \in(0,1)$. They are also destroyed endogenously if, for a given age and match quality, the idiosyncratic productivity is so low that the match surplus is negative. Both exogenous and endogenous destruction may occur for a newly formed match; a match may be immediately destroyed after being formed. Furthermore, a match is destroyed when the worker turns age $\mathrm{T}$ and dies.

Finally, we assume that wages in the match are determined as the Nash solution to a bargaining problem, and that there is free entry of firms.

\subsection{The Problem of the Agents}

\section{The Problem of the Firm}

A vacant firm posts vacancies in the labor market, and if matched with a worker, chooses whether to start producing or to remain as a vacant firm. Denote the value of a vacancy by $V$. We can write the present value of posting a vacancy for a firm as:

$$
\begin{aligned}
V= & -k+\beta\left\{q ( \theta ) ( 1 - \delta ) \sum _ { a = 0 } ^ { T - 1 } \gamma _ { a } \left(R_{a+1} \sum_{n=1}^{N} \pi_{n} \int_{\epsilon_{\min }}^{\epsilon_{\max }} \max \left\{J_{a+1, n}^{0}\left(\epsilon^{\prime}\right), V\right\} d G\left(\epsilon^{\prime}\right)(1)\right.\right. \\
& \left.\left.+\left(1-R_{a+1}\right) \int_{\epsilon_{\min }}^{\epsilon_{\max }} \max \left\{J_{a+1}^{0}\left(\epsilon^{\prime}\right), V\right\} d G\left(\epsilon^{\prime}\right)\right)+[1-q(\theta)(1-\delta)] V\right\} .
\end{aligned}
$$

The interpretation of this equation is as follows. A firm with an open vacancy pays cost $k$ to post such vacancy. The following period, whose value is discounted at rate $\beta \in(0,1)$, if the firm is matched with a worker, which happens with probability $q(\theta)$, and if the match is not destroyed for exogenous reasons, which occurs with probability $1-\delta$, the firm may start an employment relationship. A firm chooses to employ a worker of age $a$ in a match with idiosyncratic productivity $\epsilon$ if the value of a filled job with known or unknown match quality, $J_{a, n}^{0}(\epsilon)$ and $J_{a}^{0}(\epsilon)$ respectively, is greater than the value of vacancy, $V$. Since we assume non-segmented labor markets, there is probability $\gamma_{a}$ that the worker matched with the firm is of age $a$. For a worker of age $a$, there is probability $R_{a}$ that the match quality is known before production starts. And if the match quality is revealed, the probability of such match quality being $\mu_{n}$ is $\pi_{n}$. These three probabilities, $\gamma_{a}, R_{a}$ and $\pi_{n}$, are used to weight the expected value of a match for a firm. If a firm is not matched, or the match is immediately destroyed for exogenous reasons, the firm remains vacant.

A firm that employs a worker produces and pays wages during the current period. The following period, depending on the age of the worker and the value of the idiosyncratic 
productivity, the firm decides whether to continue with the match or to dissolve it and become a vacant firm. The value of an on-going match for a filled firm is given by

$$
J_{a, n}(\epsilon)=\mu_{n} \epsilon-w_{a, n}(\epsilon)+\beta\left[\mathbb{I}_{a<T} \widetilde{J}_{a+1, n}+\left(1-\mathbb{I}_{a<T}\right) V\right],
$$

where $w_{a, n}(\epsilon)$ is the wage paid to the worker, $\mathbb{I}_{a<T}$ is an indicator function that equals unity if the age of the worker is below the terminal age, and $\widetilde{J}_{a+1, n}$ is the expected continuation value of an employment relationship for a firm hiring a worker of age $a$ and does not retire, ${ }^{5}$ which is defined as

$$
\widetilde{J}_{a+1, n}=\left\{(1-\delta) \int_{\epsilon_{\min }}^{\epsilon_{\max }} \max \left\{J_{a+1, n}\left(\epsilon^{\prime}\right), V\right\} d G\left(\epsilon^{\prime}\right)+\delta V\right\} .
$$

Note that since idiosyncratic productivity, $\epsilon$, is i.i.d., the continuation value for the firm is independent of its current realization.

A firm that has just hired a worker needs to pay, in the initial period of employment, an initial cost $c$ before starting production. Hence, for newly formed matches, the value for a filled job for a firm is given by

$$
\begin{gathered}
J_{a}^{0}(\epsilon)=\left(\sum_{n=1}^{N} \pi_{n} \mu_{n}\right) \epsilon-w_{a}^{0}(\epsilon)-c+\beta\left[\sum_{n=1}^{N} \pi_{n} \mathbb{I}_{a<T} \widetilde{J}_{a+1, n}+\left(1-\mathbb{I}_{a<T}\right) V\right], \\
J_{a, n}^{0}(\epsilon)=\mu_{n} \epsilon-w_{a, n}^{0}(\epsilon)-c+\beta\left[\mathbb{I}_{a<T} \widetilde{J}_{a+1, n}+\left(1-\mathbb{I}_{a<T}\right) V\right]
\end{gathered}
$$

where $w_{a}^{0}(\epsilon)$ is the initial wage, negotiated based on the expected, not the actual, value of $\mu$; and $w_{a, n}^{0}(\epsilon)$ is the wage for those initial matches where the match quality is revealed before production starts.

\section{The Problem of the Worker}

An unemployed worker searches for a job and if matched with a firm decides whether to start working or remain unemployed. The value of unemployment, which we denote as $U_{a}$, can be written as

$$
\begin{aligned}
U_{a}= & b+\beta \mathbb{I}_{a<T}\left\{\theta q ( \theta ) ( 1 - \delta ) \left(R_{a+1} \sum_{n=1}^{N} \pi_{n} \int_{\epsilon_{\min }}^{\epsilon_{\max }} \max \left\{W_{a+1, n}^{0}\left(\epsilon^{\prime}\right), U_{a+1}\right\} d G\left(\epsilon^{\prime}\right)(5)\right.\right. \\
& \left.\left.+\left(1-R_{a+1}\right) \int_{\epsilon_{\min }}^{\epsilon_{\max }} \max \left\{W_{a+1}^{0}\left(\epsilon^{\prime}\right), U_{a+1}\right\} d G\left(\epsilon^{\prime}\right)\right)+[1-\theta q(\theta)(1-\delta)] U_{a+1}\right\} .
\end{aligned}
$$

\footnotetext{
${ }^{5}$ Note that although $\mathbb{I}_{a<T}=0$ for $a=T$, technically we still need to define the expected continuation value for a firm that is hiring a retiring worker. We set this value to $\widetilde{J}_{T+1, n}=V$.
} 
The interpretation of the value of unemployment is very similar to the value of posting a vacancy for the firm. In the current period, the unemployed worker receives $b$, which can be understood as home production, unemployment benefits, or the value of leisure. The following period, if he is not retiring, he may match with a firm and must decide whether to take the job and get the value of employment, or to remain unemployed. The value of employment depends on realization of the idiosyncratic shock, $\epsilon$, age of the worker, $a$, and whether the match quality is known before production.

The value of being employed for a worker of age $a$, when the match quality is $\mu_{n}$, is given by

$$
W_{a, n}(\epsilon)=w_{a, n}(\epsilon)+\beta \mathbb{I}_{a<T} \widetilde{W}_{a+1, n}
$$

where $\widetilde{W}_{a+1, n}$ is the expected continuation value of an employment relationship for a worker of age $a$, and who is not retiring, ${ }^{6}$ and is defined as

$$
\widetilde{W}_{a+1, n}=\left\{(1-\delta) \int_{\epsilon_{\min }}^{\epsilon_{\max }} \max \left\{W_{a+1, n}\left(\epsilon^{\prime}\right), U_{a+1}\right\} d G\left(\epsilon^{\prime}\right)+\delta U_{a+1}\right\} .
$$

In the initial period of employment, the value of employment in a match whose quality is not yet revealed is given by

$$
W_{a}^{0}(\epsilon)=w_{a}^{0}(\epsilon)+\beta \sum_{n=1}^{N} \pi_{n} \mathbb{I}_{a<T} \widetilde{W}_{a+1, n},
$$

whereas the value of employment in a match with known match quality $\mu_{n}$ is given by

$$
W_{a, n}^{0}(\epsilon)=w_{a, n}^{0}(\epsilon)+\beta \mathbb{I}_{a<T} \widetilde{W}_{a+1, n} .
$$

\subsection{Surplus, Wages, Thresholds and Flows}

\section{Surplus}

The surplus of a match is defined as the sum of what the firm and the worker gain from the match, minus what they lose: $S_{a, n}(\epsilon) \equiv J_{a, n}(\epsilon)+W_{a, n}(\epsilon)-U_{a}-V, S_{a, n}^{0}(\epsilon) \equiv$ $J_{a, n}^{0}(\epsilon)+W_{a, n}^{0}(\epsilon)-U_{a}-V$ and $S_{a}^{0}(\epsilon) \equiv J_{a}^{0}(\epsilon)+W_{a}^{0}(\epsilon)-U_{a}-V$.

Since the idiosyncratic productivity of the match, $\epsilon$, is i.i.d. and drawn every period, the continuation values for the different states of the agents do not depend on the current value of $\epsilon$. Using the previous definitions of the match surplus, as well as the value func-

\footnotetext{
${ }^{6} \mathrm{As}$ in the problem of the firm, we must define the expected continuation value for a worker who is retiring for equations (5) and (6) to be well-defined for $a=T$. We set this value to $\widetilde{W}_{T+1, n}=W_{T+1}^{0}(\epsilon)=$ $W_{T+1, n}^{0}(\epsilon)=U_{T+1}=0 \forall \epsilon$.
} 
tions from above, it is straightforward to show that the surplus of the match is a strictly increasing function of $\epsilon$. Given the assumption about wages being set as the Nash solution to a bargaining problem, it is also easy to show that the model satisfies the reservation productivity property, as is standard in this literature. In other words, there exists a single threshold for $\epsilon$ below which the termination of the match is optimal for both the firm and the worker. Such threshold corresponds to the value of $\epsilon$ that makes the match surplus zero. These thresholds, whose expressions are stated later, are denoted as $\bar{\epsilon}_{a, n}, \bar{\epsilon}_{a, n}^{0}$ and $\bar{\epsilon}_{a}^{0}$ for surpluses $S_{a, n}(\epsilon), S_{a, n}^{0}(\epsilon)$ and $S_{a}^{0}(\epsilon)$, respectively.

Using the reservation property and the previous value functions, we obtain the following expressions for the surpluses:

$$
\begin{aligned}
& S_{a, n}(\epsilon)= \mu_{n} \epsilon-b+\beta \mathbb{I}_{a<T}(1-\delta) \int_{\bar{\epsilon}_{a+1, n}}^{\epsilon_{\max }} S_{a+1, n}\left(\epsilon^{\prime}\right) d G\left(\epsilon^{\prime}\right) \\
&-\beta \mathbb{I}_{a<T} \theta q(\theta)(1-\delta)\left(R_{a+1} \sum_{n=1}^{N} \pi_{n} \int_{\bar{\epsilon}_{a+1, n}^{0}}^{\epsilon_{\max }}\left[W_{a+1, n}^{0}\left(\epsilon^{\prime}\right)-U_{a+1}\right] d G\left(\epsilon^{\prime}\right)\right. \\
&\left.+\left(1-R_{a+1}\right) \int_{\bar{\epsilon}_{a+1}^{0}}^{\epsilon_{\max }}\left[W_{a+1}^{0}\left(\epsilon^{\prime}\right)-U_{a+1}\right] d G\left(\epsilon^{\prime}\right)\right) \\
& S_{a, n}^{0}(\epsilon)=S_{a, n}(\epsilon)-c \\
& S_{a}^{0}(\epsilon)=\sum_{n=1}^{N} \pi_{n} S_{a, n}(\epsilon)-c
\end{aligned}
$$

Note that starting from $a=T$, we can recursively establish up to $a=1$ that $S_{a, n}(\epsilon)$ is strictly increasing in $\mu_{n}$. This is natural, since the current match quality does not affect the worker's outside option value.

\section{Wages}

Wages are chosen as the Nash solution to a bargaining problem, where $\eta$ is the bargaining power of the worker. Therefore, wages for an on-going match solve the following problem

$$
\max _{w_{a, n}(\epsilon)}\left(J_{a, n}(\epsilon)-V\right)^{1-\eta}\left(W_{a, n}(\epsilon)-U_{a}\right)^{\eta}
$$

Wages for newly formed matches solve similarly defined problems. Solving such problems, we find the standard sharing conditions that both worker and firm obtain a constant fraction of the match surplus (i.e. $J_{a, n}(\epsilon)-V=(1-\eta) S_{a, n}(\epsilon)$ and $W_{a, n}(\epsilon)-U_{a}=$ 
$\left.\eta S_{a, n}(\epsilon)\right)$, which delivers the following expressions for wages:

$$
\begin{gathered}
w_{a, n}(\epsilon)=\eta \mu_{n} \epsilon+(1-\eta)\left[b+\beta \mathbb{I}_{a<T} \theta q(\theta)(1-\delta) \eta\left(R_{a+1} \sum_{n=1}^{N} \pi_{n} \int_{\bar{\epsilon}_{a+1, n}^{0}}^{\epsilon_{\max }} S_{a+1, n}^{0}\left(\epsilon^{\prime}\right) d G\left(\epsilon^{\prime}\right)\right.\right. \\
\left.\left.+\left(1-R_{a+1}\right) \int_{\bar{\epsilon}_{a+1}^{0}}^{\epsilon_{\max }} S_{a+1}^{0}\left(\epsilon^{\prime}\right) d G\left(\epsilon^{\prime}\right)\right)\right] \\
w_{a, n}^{0}(\epsilon)=w_{a, n}(\epsilon)-\eta c \\
w_{a}^{0}(\epsilon)=\sum_{n=1}^{N} \pi_{n} w_{a, n}(\epsilon)-\eta c
\end{gathered}
$$

\section{Thresholds}

Destruction thresholds are defined as the level of idiosyncratic productivity that makes the surplus of the match equal to zero. For existing matches, the threshold is:

$$
\begin{aligned}
\bar{\epsilon}_{a, n}= & \frac{1}{\mu_{n}}\left\{b-\beta \mathbb{I}_{a<T}(1-\delta) \int_{\bar{\epsilon}_{a+1, n}}^{\epsilon_{\max }} S_{a+1, n}\left(\epsilon^{\prime}\right) d G\left(\epsilon^{\prime}\right)\right. \\
& +\beta \mathbb{I}_{a<T} \theta q(\theta)(1-\delta) \eta\left(R_{a+1} \sum_{n=1}^{N} \pi_{n} \int_{\bar{\epsilon}_{a+1, n}^{0}}^{\epsilon_{\max }} S_{a+1, n}^{0}\left(\epsilon^{\prime}\right) d G\left(\epsilon^{\prime}\right)\right. \\
& \left.\left.+\left(1-R_{a+1}\right) \int_{\bar{\epsilon}_{a+1}^{0}}^{\epsilon_{\max }} S_{a+1}^{0}\left(\epsilon^{\prime}\right) d G\left(\epsilon^{\prime}\right)\right)\right\}
\end{aligned}
$$

Since $S_{a+1, n}$ is increasing in the match quality $\mu_{n}$ as mentioned above, these expressions imply that the destruction thresholds are decreasing in $\mu_{n}$. Therefore, workers who are in a better quality match are less likely to leave the match.

For newly created matches, the threshold is given by

$$
\bar{\epsilon}_{a, n}^{0}=\bar{\epsilon}_{a, n}+\frac{1}{\mu_{n}} c
$$

when the match quality is immediately revealed, and

$$
\bar{\epsilon}_{a}^{0}=\frac{1}{\sum_{n=1}^{N} \pi_{n} \mu_{n}}\left(\sum_{n=1}^{N} \pi_{n} \mu_{n} \bar{\epsilon}_{a, n}+c\right)
$$


when the match quality is not revealed. ${ }^{7}$

\section{Worker Flows}

We assume that the population for every age group is unity. Hence, given the previously defined thresholds, we can write the evolution of the different states as:

$$
\begin{aligned}
1= & u_{a}+e_{a} \\
u_{a}= & {\left[1-\theta q(\theta)(1-\delta)\left\{R_{a} \sum_{n=1}^{N} \pi_{n}\left(1-G\left(\bar{\epsilon}_{a, n}^{0}\right)\right)+\left(1-R_{a}\right)\left(1-G\left(\bar{\epsilon}_{a}^{0}\right)\right)\right\}\right] u_{a-1} } \\
& +\sum_{n=1}^{N}\left[\delta+(1-\delta) G\left(\bar{\epsilon}_{a, n}\right)\right] e_{a-1, n}, \\
e_{a}= & e_{a-1}-\sum_{n=1}^{N}\left(\delta+(1-\delta) G\left(\bar{\epsilon}_{a, n}\right)\right) e_{a-1, n} \\
& +\theta q(\theta)(1-\delta)\left\{R_{a} \sum_{n=1}^{N} \pi_{n}\left(1-G\left(\bar{\epsilon}_{a, n}^{0}\right)\right)+\left(1-R_{a}\right)\left(1-G\left(\bar{\epsilon}_{a}^{0}\right)\right)\right\} u_{a-1}, \\
e_{a, n}= & \pi_{n} \theta q(\theta)(1-\delta)\left\{R_{a}\left(1-G\left(\bar{\epsilon}_{a, n}^{0}\right)\right)+\left(1-R_{a}\right)\left(1-G\left(\bar{\epsilon}_{a}^{0}\right)\right)\right\} u_{a-1} \\
& +e_{a-1, n}(1-\delta)\left(1-G\left(\bar{\epsilon}_{a, n}\right)\right) \\
e_{a}= & \sum_{n=1}^{N} e_{a, n},
\end{aligned}
$$

where $u_{a}$ and $e_{a}$ are the number of unemployed and employed workers of age $a$, and $e_{a, n}$ is the number of employed workers of age $a$ in a match with quality $\mu_{n}$. We assume that all workers start unemployed, so $u_{0}=1$, and $e_{0, n}=0$.

The aggregate unemployment and employment rates are:

$$
\begin{aligned}
u & =\frac{1}{T} \sum_{a=1}^{T} u_{a}, \\
e & =1-u .
\end{aligned}
$$

The probability that a worker matched with a firm is of age $a$ is

$$
\gamma_{a}=\frac{u_{a}}{\sum_{a=0}^{T-1} u_{a}}
$$

${ }^{7}$ The values computed using equations (15) to (17) may lie outside the domain of idiosyncratic productivity, $\left[\epsilon_{\min }, \epsilon_{\max }\right]$. In such case, we restrict the threshold value to equal the adequate boundary. 


\subsection{Equilibrium}

We assume free entry of firms, which in equilibrium implies zero expected profits from vacancy posting; this yields the following equation

$$
\begin{aligned}
k= & \beta q(\theta)(1-\delta) \sum_{a=0}^{T-1} \gamma_{a}\left(R_{a+1} \sum_{n=1}^{N} \pi_{n} \int_{\bar{\epsilon}_{a+1, n}^{0}}^{\epsilon_{\max }} J_{a+1, n}^{0}\left(\epsilon^{\prime}\right) d G\left(\epsilon^{\prime}\right)\right. \\
& \left.+\left(1-R_{a+1}\right) \int_{\bar{\epsilon}_{a+1}^{0}}^{\epsilon_{\max }} J_{a+1}^{0}\left(\epsilon^{\prime}\right) d G\left(\epsilon^{\prime}\right)\right) .
\end{aligned}
$$

The stationary market equilibrium is a set of $\left\{S_{a, n}(\epsilon), S_{a, n}^{0}(\epsilon), S_{a}^{0}(\epsilon), \bar{\epsilon}_{a, n}, \bar{\epsilon}_{a, n}^{0}, \bar{\epsilon}_{a}^{0}, \theta, e_{a, n}, e_{a}, u_{a}\right\}$ for $a \in\{1,2, \ldots, T\}$ and $n \in\{1,2, \ldots, N\}$ such that (i) the surpluses are consistent with the agents problems, and satisfy equations (9) to (11); (ii) separation decisions are individually efficient and satisfy equations (15) to (17); (iii) expected profit from posting a vacancy is zero, and satisfies equation (26); (iv) the probabilities of finding a worker/firm are consistent with the matching function; and (v) implied employment and unemployment are consistent with the above conditions, and satisfy the flow equations (18) to (24).

The existence and uniqueness of equilibrium are confirmed by solving the equilibrium equations backwards, starting from $a=T$.

\section{Numerical Simulations}

In order to assess the fit of the model, we first parameterize it following the literature and by calibrating some of the values to match the main U.S. labor market facts for the period 1976-2005. We then simulate the model, and finally compare its life-cycle implications with the empirical patterns described above. Let us discuss the calibration and simulation results in more detail.

\subsection{Parameterization}

We set a model period to one quarter, and set the discount factor $\beta$ to 0.99 . We assume working life to be 50 years, which implies $T=200$.

We assume a standard Cobb-Douglas matching function $m(u, v)=\kappa u^{\alpha} v^{1-\alpha}$. We set both the worker's bargaining power $\eta$ and the unemployment elasticity of matches $\alpha$ to 0.5 , which are conventional choices in the literature. There is no agreement in the literature on the distribution of $\epsilon$, so for simplicity, we assume that it follows a uniform distribution, $\epsilon \sim U[0,1]$ 
The remaining parameters are determined by solving for the steady state of the model and matching specific long-run labor market facts. Following Shimer (2005), we normalize the steady state value of $\theta$ to 1 , and choose the vacancy cost $k$ such that the zero profit condition for posting a vacancy (26) holds for $\theta=1$. We then choose the scaling parameter of the matching function $\kappa$ to match the quarterly job finding rate of 67.1 percent, which is the average figure for all age groups. The training cost $c$ is set to 32 percent of quarterly average wage, following Mortensen (1994). The value of $b$ is chosen such that its ratio to the average wage equals 50 percent, which lies within the range of values used in the literature. ${ }^{8}$ We choose the exogenous separation rate $\delta$ to match the unemployment rate of the youngest five-year age group, 16.3 percent.

The parameters related to the quality of the match are chosen as follows. We assume that the probability of immediate revelation of match quality $R_{a}$ is a declining function with the following form: $R_{a}=r_{a}(a-1)$ for $a \in\{1,2, \ldots, T\}$. We calibrate $r_{a}$ to match the quarterly job finding rate of the youngest five-year age group, 72.7 percent. The idea behind this formulation of $R_{a}$ is that it is difficult to assess, prior to entering an employment relationship, the match quality of young workers with little employment history. Such assessment should become easier as workers get older and accumulate employment history. We assume that $\mu_{n}$ lies on $N=20$ grid points, ${ }^{9}$ equispaced on the interval $\left[\mu_{1}, \mu_{N}\right]$, with equal probability. We normalize $\mu_{1}$ to 1 , and calibrate $\mu_{N}$ to match the average unemployment rate for all age groups for the period of study, 6.1 percent.

The resulting parameter values are summarized in Table 1.

\subsection{Results}

We now compare the unemployment rate, the separation rate, and the job finding rate from the model with those in the U.S. data. The data shown in Section 2 display the three rates averaged by five-year age group. Since the frequency of the model is quarterly, we take the averages for 20-period groups to correspond with the five-year age groups of the data. We present first the results for the finding rate, then the separation rate, and finally the unemployment rate. Showing the results in this order allows us to explain how the different mechanisms of the model interact to deliver the results.

Figure 2c plots the job finding rate in the model, along with its empirical counterpart. The calibration targets the average job finding rate for all age groups, and it also separately

\footnotetext{
${ }^{8}$ Two papers often cited as examples of bounds for this parameter are Shimer (2005) and Hagedorn and Manovskii (2008), who set $b$ to 40 percent and 95 percent of average labor productivity, respectively. As noted by Shimer (2005), wages in their model are very close to productivity, so $b$ represents almost the same fraction of productivity as of wages.

${ }^{9}$ Our numerical results are not very sensitive to the value of $N$, so long as it is sufficiently large.
} 
targets the average job finding rate of the youngest age group. The finding rates for age groups other than the youngest one are not directly targeted, and are determined endogenously in the model. We observe that the model fits the data very well, capturing the steady decline in the finding rate as workers age. The intuition for why the model is able to deliver a decline in this rate is a combination of finite horizon and uncertainty regarding the quality of matches.

The finite nature of a worker's career reduces the expected value of hiring older workers. This is already present in the model of Cheron, Hairault, and Langot (2008), and is known as the horizon effect. All workers match with firms at the same rate, since we assume non-segmented labor markets. However, the shorter horizon of older workers makes them less valuable to the firm, unless they have high productivity levels. This, in turn, implies that after matching, the probability of firms and workers agreeing to start production is lower as age increases, which reduces the finding rate of older workers.

Furthermore, the probability that match quality is immediately revealed after matching is higher for older workers. The matches whose quality is immediately revealed to be low do not turn into employment relationships, which lowers the finding rate of older workers. Instead, matches with young workers less frequently have quality immediately revealed, and this provides incentives for firms and workers to start the employment relationship and to delay the match dissolution decision.

While the horizon effect is qualitatively important, it is the existence of match quality, together with the increasing probability of immediate revelation of its level, that quantitatively dominates the simulation results.

The results for the separation rate are set forth in Figure $2 \mathrm{~b}$. The parameterization of the model targets none of the separation rates in the data, and we observe that the model does a fairly good job at reproducing the empirical behavior of this variable. While the model delivers a separation rate for the youngest age group that is higher than in the actual data, it is able to produce a declining rate as workers age; the simulation levels are close to the empirical counterparts for all other age groups.

Unlike the finding rate, where the horizon effect delivers, at least qualitatively, a declining finding rate as in the data, the separation rate produced by the model, which uses only a horizon effect, is counterfactually upward-sloping. However, the inclusion of uncertain match quality, combined with horizon effects, causes the model to reproduce the declining job separation rate in the data. Let us explain in more detail the mechanism at work.

The quality of the match is unknown for many newly formed matches, but is revealed after a period of employment. A large proportion of the matches whose quality is revealed to be low are then terminated. The fact that young workers enter the labor market without 
a job makes it more likely that they are in their first period of employment, whose match quality may be unknown. Furthermore, compared to matches with older workers, a higher proportion of newly formed matches with younger workers are of unknown match quality. Finally, since the opportunity cost of staying in a match of low quality is higher for young workers than for older ones due to the horizon effect, matches with younger workers are more likely to be destroyed. All these effects combined produce in the model a separation rate that declines with age, and that is close to that of the actual data.

Note, however, that compared to its empirical counterpart, the predicted separation rate declines more from the youngest to the second youngest age group. This stems from the feature of the model that match quality is revealed after one period of tenure. The model prediction is thus likely to be improved, if we incorporate learning of match quality, for example, as in Pries and Rogerson (2005)..$^{10}$

Finally, Figure 2a plots the unemployment rate in the model and in the U.S. data. As discussed above, our calibration targets the average unemployment rate, as well as the unemployment rate of those aged 16 to 20 , but otherwise the unemployment rate for each age is determined endogenously in the model. Figure 2 a shows that the model predicts the life-cycle pattern of unemployment rates quite well. We observe that the model reproduces the sharp decline for workers who have already been in the labor market for 5 to 10 years, and rates decrease at a much slower pace after the age of 30 .

The ability of the model to reproduce the empirically observed unemployment rate can be understood as the combination of the effects explained above. Workers enter the labor market without a job, and despite having high finding rates, they are also more likely to quickly separate from the firm and become unemployed. These three factors combine to produce higher unemployment rates for young workers, which decline with age as workers find higher quality matches and separate less often.

\section{$5 \quad$ Efficiency}

We have shown that the market equilibrium of the model reproduces the empirically observed declining unemployment, separation and finding rates. We now explore the issue of the efficiency of such an equilibrium by comparing its allocation with a constrained efficient allocation of a benevolent social planner.

While the analysis of efficiency in a life-cycle labor search model is pursued in Cheron,

\footnotetext{
${ }^{10}$ In Pries and Rogerson (2005), however, endogenous separation occurs only in the period in which match quality is revealed; all separations beyond that period are exogenous. Incorporating learning into the framework of our paper, in which endogenous separation occurs throughout the match, is not a straightforward task.
} 
Hairault, and Langot (2008), our analysis below differs in two dimensions. First, our model features random match quality, which is absent in these authors' model. Second, while Cheron, Hairault, and Langot (2008) focuses on the qualitative analysis of efficiency, we examine quantitative implications of the efficient allocation and optimal policies.

We assume that the social planner maximizes the discounted present value of the steady state net aggregate output, ${ }^{11}$ taking as given the single labor market, as well as the search friction in this market. ${ }^{12}$ As shown by Cheron, Hairault, and Langot (2008), the decentralized equilibrium of a life-cycle search model with a single labor market is in general inefficient, even when the Hosios condition holds. ${ }^{13}$ This is because there is an externality arising from the fact that unemployed workers of different ages, who will lead to new matches with different surpluses, are pooled in the same market. Unlike the usual search externality, this intergenerational externality is not internalized by the Hosios condition, hence the inefficiency persists.

We first confirm that such inefficiency implication carries over to our environment with random match quality. We then quantitatively assess such inefficiency, by numerically computing the efficient allocation and comparing the results with those of the previous section. Finally, we explore policies that achieve the efficient allocation.

\subsection{The Planner's problem}

The planner's problem is to choose $\left\{e_{a, n, t}, u_{a, t}, \bar{\epsilon}_{a, n, t+1}, \bar{\epsilon}_{a, n, t+1}^{0}, \bar{\epsilon}_{a, t+1}^{0}, \theta_{t}\right\}$ for $a \in\{1,2, \ldots, T\}$, $n \in\{1,2, \ldots, N\}$ and $t \in\{0,1, \ldots, \infty\}$, given $e_{0, n, t}=0$ for all $n$ and $t$ and $u_{0, t}=1$ for all $t$, to maximize

$$
\begin{aligned}
& \sum_{t=1}^{\infty} \beta^{t-1}\left[\theta _ { t - 1 } q ( \theta _ { t - 1 } ) ( 1 - \delta ) \left\{\sum _ { a = 1 } ^ { T } u _ { a - 1 , t - 1 } \sum _ { n = 1 } ^ { N } \pi _ { n } \left\{R_{a} \int_{\bar{\epsilon}_{a, n, t}^{0}}^{\epsilon_{\max }}\left(\mu_{n} \epsilon-c\right) d G(\epsilon)\right.\right.\right. \\
& \left.\left.+\left(1-R_{a}\right) \int_{\bar{\epsilon}_{a, t}^{0}}^{\epsilon_{\max }}\left(\mu_{n} \epsilon-c\right) d G(\epsilon)\right\}\right\} \\
& \left.+(1-\delta) \sum_{a=1}^{T} \sum_{n=1}^{N} e_{a-1, n, t-1} \mu_{n} \int_{\bar{\epsilon}_{a, n, t}}^{\epsilon_{\max }} \epsilon d G(\epsilon)+b \sum_{a=1}^{T} u_{a, t}-\theta_{t} k \sum_{a=0}^{T-1} u_{a, t}\right],
\end{aligned}
$$

\footnotetext{
${ }^{11}$ Alternatively, one may assume that the social planner maximizes the steady state net aggregate output, and conduct the comparison with the market allocation by taking the limit $\beta \rightarrow 1$. Such an assumption simplifies the analysis without altering the main results, but we do not employ this approach here, so as to enable a direct comparison between the planner's allocation and the market allocation shown in the previous section.

${ }^{12}$ Alternatively, one may consider a social planner who is able to segment the labor market by age. The allocation would be more efficient in that case, since such a planner is less constrained.

${ }^{13}$ As claimed in Cheron, Hairault, and Langot (2008), however, the decentralized equilibrium in a standard life-cycle search model is efficient when the Hosios condition holds, if the labor market is completely segmented into submarkets by worker age.
} 
subject to the flow equations corresponding to (18) to (23), as well as the steady state condition that all variables are stationary over time. The first term corresponds to aggregate net output, in period $t$, from newly created matches. Each new match has quality $\mu_{n}$ with probability $\pi_{n}$, which leads to net output $\mu_{n} \epsilon-c$ if the match proceeds into an employment relationship. Moreover, match quality is immediately revealed with probability $R_{a}$ and not immediately revealed otherwise, which leads to different thresholds for starting an employment relationship, $\bar{\epsilon}_{a, n, t}^{0}$ and $\bar{\epsilon}_{a, t}^{0}$. The second term corresponds to the net output from the existing matches, and the third term is the aggregate flow value of unemployment. The final term denotes the aggregate flow cost of creating vacancies.

As shown in Appendix, taking the first-order conditions, imposing the steady state condition and rearranging, we obtain the following expressions that characterize the planner's allocation.

$$
\begin{aligned}
& \mu_{n} \bar{\epsilon}_{a, n}+\beta \mathbb{I}_{a<T}(1-\delta) \mu_{n} \int_{\bar{\epsilon}_{a+1, n}}^{\epsilon_{\max }}\left(\epsilon-\bar{\epsilon}_{a+1, n}\right) d G(\epsilon) \\
& =\quad b-\theta k \mathbb{I}_{a<T}+\beta \mathbb{I}_{a<T} \theta q(\theta)(1-\delta) \sum_{n=1}^{N} \pi_{n}\left\{R_{a+1} \int_{\bar{\epsilon}_{a+1, n}^{0}}^{\epsilon_{\max }} \mu_{n}\left(\epsilon-\bar{\epsilon}_{a+1, n}^{0}\right) d G(\epsilon)\right. \\
& \left.+\left(1-R_{a+1}\right) \int_{\bar{\epsilon}_{a+1}^{0}}^{\epsilon_{\max }} \mu_{n}\left(\epsilon-\bar{\epsilon}_{a+1}^{0}\right) d G(\epsilon)\right\}, \\
& \left(\sum_{n=1}^{N} \pi_{n} \mu_{n}\right) \bar{\epsilon}_{a}^{0}=\sum_{n=1}^{N} \pi_{n} \mu_{n} \bar{\epsilon}_{a, n}+c, \\
& k=\bar{\epsilon}_{a, n}^{0}=\mu_{n} \bar{\epsilon}_{a, n}+c, \\
& \quad \beta q(\theta)[1-\alpha(\theta)](1-\delta) \sum_{a=0}^{T-1} \gamma_{a} \sum_{n=1}^{N} \pi_{n}\left\{R_{a+1} \int_{\bar{\epsilon}_{a+1, n}^{0}}^{\epsilon_{\max }} \mu_{n}\left(\epsilon-\bar{\epsilon}_{a+1, n}^{0}\right) d G(\epsilon)\right. \\
& \left.+\left(1-R_{a+1}\right) \int_{\bar{\epsilon}_{a+1}^{0}}^{\epsilon_{\max }} \mu_{n}\left(\epsilon-\bar{\epsilon}_{a+1}^{0}\right) d G(\epsilon)\right\},
\end{aligned}
$$

where $\gamma_{a}$ is, as before, the fraction of age $a$ workers searching for a job, and $\alpha(\theta) \equiv$ $-\theta q^{\prime}(\theta) / q(\theta)$.

Let us now confirm that the equilibrium allocation does not coincide with the planner's allocation, even when the Hosios condition $\eta=\alpha(\theta)$ holds. To see this, substitute (30) 
into (27) to obtain

$$
\begin{aligned}
& \mu_{n} \bar{\epsilon}_{a, n}+\beta \mathbb{I}_{a<T}(1-\delta) \mu_{n} \int_{\bar{\epsilon}_{a+1, n}}^{\epsilon_{\max }}\left(\epsilon-\bar{\epsilon}_{a+1, n}\right) d G(\epsilon) \\
= & b+\beta \mathbb{I}_{a<T} \theta q(\theta)(1-\delta) \sum_{n=1}^{N} \pi_{n}\left\{R_{a+1} \int_{\bar{\epsilon}_{a+1, n}^{0}}^{\epsilon_{\max }} \mu_{n}\left(\epsilon-\bar{\epsilon}_{a+1, n}^{0}\right) d G(\epsilon)\right. \\
& \left.+\left(1-R_{a+1}\right) \int_{\bar{\epsilon}_{a+1}^{0}}^{\epsilon_{\max }} \mu_{n}\left(\epsilon-\bar{\epsilon}_{a+1}^{0}\right) d G(\epsilon)\right\} \\
& -\beta \mathbb{I}_{a<T} \theta q(\theta)[1-\alpha(\theta)](1-\delta) \sum_{a=0}^{T-1} \gamma_{a} \sum_{n=1}^{N} \pi_{n}\left\{R_{a+1} \int_{\bar{\epsilon}_{a+1, n}^{0}}^{\epsilon_{\max }} \mu_{n}\left(\epsilon-\bar{\epsilon}_{a+1, n}^{0}\right) d G(\epsilon)\right. \\
& \left.+\left(1-R_{a+1}\right) \int_{\bar{\epsilon}_{a+1}^{0}}^{\epsilon_{\max }} \mu_{n}\left(\epsilon-\bar{\epsilon}_{a+1}^{0}\right) d G(\epsilon)\right\} .
\end{aligned}
$$

The corresponding expression for the equilibrium allocation, obtained from (15) and the fact that

$$
\begin{aligned}
& S_{a, n}(\epsilon)=S_{a, n}\left(\bar{\epsilon}_{a, n}\right)+\mu_{n}\left(\epsilon-\bar{\epsilon}_{a, n}\right)=\mu_{n}\left(\epsilon-\bar{\epsilon}_{a, n}\right), \\
& S_{a, n}^{0}(\epsilon)=S_{a, n}^{0}\left(\bar{\epsilon}_{a, n}^{0}\right)+\mu_{n}\left(\epsilon-\bar{\epsilon}_{a, n}^{0}\right)=\mu_{n}\left(\epsilon-\bar{\epsilon}_{a, n}^{0}\right)
\end{aligned}
$$

and

$$
S_{a}^{0}(\epsilon)=S_{a}^{0}\left(\bar{\epsilon}_{a}^{0}\right)+\sum_{n=1}^{N} \pi_{n} \mu_{n}\left(\epsilon-\bar{\epsilon}_{a}^{0}\right)=\sum_{n=1}^{N} \pi_{n} \mu_{n}\left(\epsilon-\bar{\epsilon}_{a}^{0}\right)
$$

is

$$
\begin{aligned}
& \mu_{n} \bar{\epsilon}_{a, n}+\beta \mathbb{I}_{a<T}(1-\delta) \mu_{n} \int_{\bar{\epsilon}_{a+1, n}}^{\epsilon_{\max }}\left(\epsilon-\bar{\epsilon}_{a+1, n}\right) d G(\epsilon) \\
= & b+\beta \mathbb{I}_{a<T} \theta q(\theta)(1-\delta) \eta \sum_{n=1}^{N} \pi_{n}\left\{R_{a+1} \int_{\bar{\epsilon}_{a+1, n}^{0}}^{\epsilon_{\max }} \mu_{n}\left(\epsilon-\bar{\epsilon}_{a+1, n}^{0}\right) d G(\epsilon)\right. \\
& \left.+\left(1-R_{a+1}\right) \int_{\bar{\epsilon}_{a+1}^{0}}^{\epsilon_{\max }} \mu_{n}\left(\epsilon-\bar{\epsilon}_{a+1}^{0}\right) d G(\epsilon)\right\} .
\end{aligned}
$$

Clearly, (32) does not coincide with (31) even if $\eta=\alpha(\theta)$, since

$$
\sum_{n=1}^{N} \pi_{n}\left\{R_{a+1} \int_{\bar{\epsilon}_{a+1, n}^{0}}^{\epsilon_{\max }} \mu_{n}\left(\epsilon-\bar{\epsilon}_{a+1, n}^{0}\right) d G(\epsilon)+\left(1-R_{a+1}\right) \int_{\bar{\epsilon}_{a+1}^{0}}^{\epsilon_{\max }} \mu_{n}\left(\epsilon-\bar{\epsilon}_{a+1}^{0}\right) d G(\epsilon)\right\},
$$


in general, varies with $a$ and thus does not equal

$$
\sum_{a=0}^{T-1} \gamma_{a} \sum_{n=1}^{N} \pi_{n}\left\{R_{a+1} \int_{\bar{\epsilon}_{a+1, n}^{0}}^{\epsilon_{\max }} \mu_{n}\left(\epsilon-\bar{\epsilon}_{a+1, n}^{0}\right) d G(\epsilon)+\left(1-R_{a+1}\right) \int_{\bar{\epsilon}_{a+1}^{0}}^{\epsilon_{\max }} \mu_{n}\left(\epsilon-\bar{\epsilon}_{a+1}^{0}\right) d G(\epsilon)\right\}
$$

This confirms that the Hosios condition does not achieve efficiency; the intuition can be understood as follows. The fact that old workers are close to retirement implies that their social value as unemployed workers is lower than their younger counterparts. Given the single labor market, however, the planner's cost of creating a match, $k / q(\theta)$, is independent of worker age. Thus, it is relatively costly for the planner to terminate the matches of old workers and to assign them into the unemployment pool. This mechanism also causes the job finding rate of older workers to be higher in the planner's allocation, since the social planner is reluctant to immediately terminate the newly created matches of old workers. Firms and workers in the decentralized equilibrium, however, do not internalize such social cost, hence older workers separate from the match too frequently compared to those in the planner's allocation. This lowers the expected value of posting vacancies and reduce vacancies, hence exerting negative externalities to unemployed workers of other ages.

\subsection{Numerical Simulation of the Planner's Allocation}

Since, as we have shown, the planner's allocation differs from that of the decentralized equilibrium, we are interested in comparing how far apart these two allocations are. In this section, we compute the planner's allocation numerically, and compare the result with the equilibrium allocation. The parameters used are the same as in Section 4, except for the bargaining power $\eta$, which does not appear in the planner's condition. Note that since we impose the Hosios condition $\alpha=\eta$ for the equilibrium allocation, the difference in these two allocations below result solely from the life-cycle feature of the model.

Figure 3 plots the unemployment rate, the job separation rate, and the job finding rate in the decentralized equilibrium and the planner's allocation. We observe that these two allocations are almost identical for these three rates. The evident difference is for the age group 61 to 65 , for which the unemployment and separation rates are slightly lower in the planner's allocation, whereas the finding rate is considerably higher. This, as explained above, is due to the fact that the planner realizes that placing old workers, who have shorter time to retirement and thus lower values in future matches, in the unemployment pool exerts negative externalities on other workers searching for employment.

That the difference in the allocation of the planner and the decentralized market appears only for very old workers can be understood from the two expressions at the end 
of Section 5.1. These correspond to, respectively, the expected surplus from a new match with a worker of age $a$, and its average weighted by the fraction of workers of each age searching for a job; as we have shown, the difference between these two values generates the inefficiency of the decentralized equilibrium. For very old workers who are close to retirement, this difference is large due to the horizon effect, resulting in the difference of two allocations observed in Figure 3a. For other workers, however, the expected surplus from a new match is fairly close to its average value in the economy. This is because, due to discounting, the differences in distance to retirement have only small effects on the match surplus of workers who are not close to retirement.

\subsection{Optimal Policy}

We now explore how governments can achieve the efficient allocation through labor market policies. As we show below, a combination of hiring subsidy and age-dependent firing taxes accomplishes this objective.

Suppose the government imposes on firms firing taxes $F_{a}$ to separate with a worker of age $a$. This firing tax applies to workers in existing matches, as well as those in newly created ones. Further, suppose that the government provides hiring subsidy $H$ for posting a vacancy. Note that $F_{a}$ and $H$ are not restricted to being positive; $F_{a}<0$ implies a firing subsidy, and $H<0$ implies a hiring tax. As shown in the Appendix, the job creation and destruction conditions become

$$
\begin{aligned}
& k-H= \beta q(\theta)(1-\delta)(1-\eta) \sum_{a=0}^{T-1} \gamma_{a}\left(R_{a+1} \sum_{n=1}^{N} \pi_{n} \int_{\bar{\epsilon}_{a+1, n}^{0}}^{\epsilon_{\max }} S_{a+1, n}^{0}\left(\epsilon^{\prime}\right) d G\left(\epsilon^{\prime}\right)\right. \\
&\left.+\left(1-R_{a+1}\right) \int_{\bar{\epsilon}_{a+1}^{0}}^{\epsilon_{\max }} S_{a+1}^{0}\left(\epsilon^{\prime}\right) d G\left(\epsilon^{\prime}\right)\right)-\beta q(\theta)(1-\delta)(1-\eta) \sum_{a=0}^{T-1} \gamma_{a} F_{a+1}, \\
& \bar{\epsilon}_{a, n}= \frac{1}{\mu_{n}}\left\{b-F_{a}+\beta \mathbb{I}_{a<T}(1-\delta) F_{a+1}-\beta \mathbb{I}_{a<T}(1-\delta) \int_{\bar{\epsilon}_{a+1, n}}^{\epsilon_{\max }} S_{a+1, n}\left(\epsilon^{\prime}\right) d G\left(\epsilon^{\prime}\right)\right. \\
&+\beta \mathbb{I}_{a<T} \theta q(\theta)(1-\delta) \eta\left(R_{a+1} \sum_{n=1}^{N} \pi_{n} \int_{\bar{\epsilon}_{a+1, n}^{0}}^{\epsilon_{\max }} S_{a+1, n}^{0}\left(\epsilon^{\prime}\right) d G\left(\epsilon^{\prime}\right)\right. \\
&\left.\left.+\left(1-R_{a+1}\right) \int_{\bar{\epsilon}_{a+1}^{0}}^{\epsilon_{\max }} S_{a+1}^{0}\left(\epsilon^{\prime}\right) d G\left(\epsilon^{\prime}\right)\right)\right\} \\
& \bar{\epsilon}_{a, n}^{0}=\bar{\epsilon}_{a, n}+\frac{1}{\mu_{n}} c
\end{aligned}
$$




$$
\bar{\epsilon}_{a}^{0}=\frac{1}{\sum_{n=1}^{N} \pi_{n} \mu_{n}}\left(\sum_{n=1}^{N} \pi_{n} \mu_{n} \bar{\epsilon}_{a, n}+c\right) .
$$

By comparing these conditions with the planner's conditions (27)-(30), we observe that efficient allocation can be achieved by setting the firing tax $F_{a}$ recursively as

$$
\begin{aligned}
F_{a}= & 0 \text { for } a=T, \\
F_{a}= & \beta(1-\delta) F_{a+1}+\theta k-\beta \theta q(\theta)(1-\delta)(1-\eta)\left\{R_{a+1} \sum_{n=1}^{N} \pi_{n} \int_{\bar{\epsilon}_{a+1, n}^{0}}^{\epsilon_{\max }} S_{a+1, n}^{0}\left(\epsilon^{\prime}\right) d G\left(\epsilon^{\prime}\right)\right. \\
& \left.+\left(1-R_{a+1}\right) \int_{\bar{\epsilon}_{a+1}^{0}}^{\epsilon_{\max }} S_{a+1}^{0}\left(\epsilon^{\prime}\right) d G\left(\epsilon^{\prime}\right)\right\} \text { for } a \in\{1,2, \ldots, T-1\},
\end{aligned}
$$

and choosing the hiring subsidy $H$ as

$$
H=\beta q(\theta)(1-\delta)(1-\eta) \sum_{a=0}^{T-1} \gamma_{a} F_{a+1},
$$

where $\theta$ corresponds to market tightness in the planner's allocation. It is important to note that implementing such an optimal policy does not require the government to recognize the quality of each match.

The upper panel of Figure 4 plots the optimal firing tax $F_{a}$ for the parameters used in the previous section. We observe that $F_{a}$ equals zero for workers in the terminal period, is positive for middle-aged and older workers, and slightly negative for workers of all other ages. This implies taxing the firing of relatively old workers, and subsidizing the firing of relatively young ones. As observed from (34), however, what really matters for the separation threshold is $F_{a}-\beta(1-\delta) F_{a+1}$, which subtracts the firing tax next period, discounted and adjusted with the probability that there is no exogenous separation. This effective firing tax, where $F_{T+1}$ is set to 0 , is plotted in the bottom panel of Figure 4 . We observe that this value is almost zero except for workers very close to retirement. In other words, since what matters is the effective firing cost, even though the firing cost is slightly negative for young workers, the government is not effectively encouraging the termination of matches for young workers, but deterring the firing of older workers. This is consistent with our analysis, which compares the allocation of the decentralized equilibrium with that of the planner.

The corresponding value of $H$, computed from (39), is 0.0289 . This is a relatively small subsidy, corresponding to roughly $7 \%$ of the flow cost of posting a vacancy. The overall conclusion is that the optimal allocation can be achieved by providing firms disincentives to fire workers very close to retirement, and small incentives to post more vacancies. 


\section{Conclusions}

Labor market stocks and flow rates differ greatly across age groups. When studying U.S. disaggregated data by age, we find that the unemployment rate, the job separation rate, and the job finding rate are all declining as workers get older. While there are papers that account for the inverted U-shape of the employment-to-population ratio across ages, their models cannot jointly explain these three facts.

This paper builds, calibrates, and simulates a search and matching model of the labor market, where workers are finitely lived. The model features random match quality, which, with positive probability, is not revealed until after employment begins. We find that the different distances to retirement of workers of various ages, and the revelation of ex ante unknown match quality, allow the model to reproduce the empirically observed declining unemployment, job finding, and job separation rates. The model, however, displays job separation rates for very young workers that are too high compared to the actual data.

This paper then explores the efficiency implication of the model. As shown in the literature, the equilibrium turns out to be inefficient even when the Hosios condition holds. Our simulations show that the difference between the equilibrium and the planner's allocation is small for young and prime-aged workers, but that the job finding rate for very old workers differs substantially between the two allocations. We then pursue an optimal policy that achieves the planner's allocation, and find that a combination of hiring subsidy and age-dependent firing taxes accomplishes this task. Importantly, this optimal policy does not depend on match quality, which enhances its practical applicability. 


\section{References}

Arcidiacono, P. (2003): "The Dynamic Implications of Search Discrimination," Journal of Public Economics, 87(7-8), 1681-1706.

Cheron, A., J. Hairault, and F. Langot (2008): "Life-Cycle Equilibrium Unemployment," IZA Discussion Papers.

Hagedorn, M., and I. Manovskit (2008): "The Cyclical Behavior of Equilibrium Unemployment and Vacancies Revisited," American Economic Review, 98(4), 1692-1706.

Hahn, V. (2009): "Search, Unemployment, and Age," Journal of Economic Dynamics and Control, 33(6), 1361-1378.

Hosios, A. (1990): "On the Efficiency of Matching and Related Models of Search and Unemployment," Review of Economic Studies, 57(2), 279-298.

Jovanovic, B. (1979): "Job Matching and the Theory of Turnover," Journal of Political Economy, 87(5).

- (1984): "Matching, Turnover, and Unemployment," Journal of Political Economy, 92(1), 108-122.

Menzio, G., I. Telyukova, And L. Visschers (2010): "Directed Search over the LifeCycle," Mimeo.

Mortensen, D. (1994): "Reducing Supply-Side Disincentives to Job Creation," in Reducing Unemployment: Current Issues and Policy Options, pp. 189-220. Kansas City: Federal Reserve Bank of Kansas City.

Pissarides, C. (1992): "Loss of Skill During Unemployment and the Persistence of Employment Shocks," Quarterly Journal of Economics, 107(4), 1371-1391.

Pries, M., And R. Rogerson (2005): "Hiring Policies, Labor Market Institutions, and Labor Market Flows," Journal of Political Economy, 113(4).

Shimer, R. (2005): "The Cyclical Behavior of Equilibrium Unemployment and Vacancies," American Economic Review, 95(1), 25-49. 


\section{Appendix}

\section{Solving the Planner's Problem}

Using $u_{a, t}=1-\sum_{n=1}^{N} e_{a, n, t}$ and rewriting the objective function, the planner's problem becomes

$$
\begin{aligned}
& \max \sum_{t=1}^{\infty} \beta^{t-1}\left[\theta _ { t - 1 } q ( \theta _ { t - 1 } ) ( 1 - \delta ) \left\{\sum _ { a = 1 } ^ { T } ( 1 - \sum _ { n = 1 } ^ { N } e _ { a - 1 , n , t - 1 } ) \sum _ { n = 1 } ^ { N } \pi _ { n } \left\{R_{a} \int_{\bar{\epsilon}_{a, n, t}^{0}}^{\epsilon_{\max }}\left(\mu_{n} \epsilon-c\right) d G(\epsilon)\right.\right.\right. \\
& \left.\left.+\left(1-R_{a}\right) \int_{\bar{\epsilon}_{a, t}^{0}}^{\epsilon_{\max }}\left(\mu_{n} \epsilon-c\right) d G(\epsilon)\right\}\right\} \\
& \left.+(1-\delta) \sum_{a=1}^{T} \sum_{n=1}^{N} e_{a-1, n, t-1} \mu_{n} \int_{\bar{\epsilon}_{a, n, t}}^{\epsilon_{\max }} \epsilon d G(\epsilon)+b \sum_{a=1}^{T}\left(1-\sum_{n=1}^{N} e_{a, n, t}\right)-\theta_{t} k \sum_{a=0}^{T-1}\left(1-\sum_{n=1}^{N} e_{a, n, t}\right)\right],
\end{aligned}
$$

where the maximization is with respect to $e_{a, n, t}, \epsilon_{a, n, t}, \bar{\epsilon}_{a, n, t}^{0}, \bar{\epsilon}_{a, t}^{0}, \theta_{t}$, and is subject to $e_{0, n, t}=0$ for all $n$ and $t$, and

$$
\begin{aligned}
e_{a, n, t}= & \theta_{t-1} q\left(\theta_{t-1}\right)(1-\delta)\left(1-\sum_{n=1}^{N} e_{a-1, n, t-1}\right) \pi_{n}\left\{R_{a} \int_{\bar{\epsilon}_{a, n, t}^{0}}^{\epsilon_{\max }} d G(\epsilon)+\left(1-R_{a}\right) \int_{\bar{\epsilon}_{a, t}^{0}}^{\epsilon_{\max }} d G(\epsilon)\right\} \\
& +e_{a-1, n, t-1}(1-\delta) \int_{\bar{\epsilon}_{a, n, t}}^{\epsilon_{\max }} d G(\epsilon)
\end{aligned}
$$

for $a=1,2 \ldots, T$ and for all $n$ and $t$.

Let $\lambda_{a, n, t}$ be the multipliers on the constraint. Then, the first-order conditions are

$$
\begin{gathered}
-b+\theta_{t} k+\lambda_{a, n, t}-\beta(1-\delta)\left\{\theta _ { t } q ( \theta _ { t } ) \sum _ { n = 1 } ^ { N } \pi _ { n } \left\{R_{a+1} \int_{\bar{\epsilon}_{a+1, n, t+1}^{0}}^{\epsilon_{\max }}\left(\mu_{n} \epsilon-c\right) d G(\epsilon)\right.\right. \\
\left.\left.+\left(1-R_{a+1}\right) \int_{\bar{\epsilon}_{a+1, t+1}^{0}}^{\epsilon_{\max }}\left(\mu_{n} \epsilon-c\right) d G(\epsilon)\right\}-\mu_{n} \int_{\bar{\epsilon}_{a+1, n, t+1}}^{\epsilon_{\max }} \epsilon d G(\epsilon)\right\} \\
=-\beta \theta_{t} q\left(\theta_{t}\right)(1-\delta) \sum_{n=1}^{N} \lambda_{a+1, n, t+1} \pi_{n}\left\{R_{a+1} \int_{\bar{\epsilon}_{a+1, n, t+1}^{0}}^{\epsilon_{\max }} d G(\epsilon)+\left(1-R_{a+1}\right) \int_{\bar{\epsilon}_{a+1, t+1}^{0}}^{\epsilon_{\max }} d G(\epsilon)\right\} \\
+\beta \lambda_{a+1, n, t+1}(1-\delta) \int_{\bar{\epsilon}_{a+1, n, t+1}}^{\epsilon_{\max }} d G(\epsilon), \\
-b+\lambda_{T, n, t}=0 \\
(1-\delta) g\left(\bar{\epsilon}_{a, n, t}\right)\left[-\mu_{n} \bar{\epsilon}_{a, n, t}+\lambda_{a, n, t}\right]=0
\end{gathered}
$$




$$
\begin{aligned}
& \theta_{t-1} q\left(\theta_{t-1}\right)(1-\delta)\left(1-\sum_{n=1}^{N} e_{a-1, n, t-1}\right) \pi_{n} R_{a} g\left(\bar{\epsilon}_{a, n, t}^{0}\right)\left[-\mu_{n} \bar{\epsilon}_{a, n, t}^{0}+c+\lambda_{a, n, t}\right]=0, \quad \text { (43) } \\
& \theta_{t-1} q\left(\theta_{t-1}\right)(1-\delta)\left(1-\sum_{n=1}^{N} e_{a-1, n, t-1}\right)\left(1-R_{a}\right) g\left(\bar{\epsilon}_{a, t}^{0}\right) \sum_{n=1}^{N} \pi_{n}\left[-\mu_{n} \bar{\epsilon}_{a, t}^{0}+c+\lambda_{a, n, t}\right]=0, \\
& \quad \beta q\left(\theta_{t}\right)\left[1-\alpha\left(\theta_{t}\right)\right](1-\delta) \sum_{a=1}^{T}\left[( 1 - \sum _ { n = 1 } ^ { N } e _ { a - 1 , n , t } ) \sum _ { n = 1 } ^ { N } \pi _ { n } \left\{R_{a} \int_{\bar{\epsilon}_{a, n, t+1}^{0}}^{\epsilon_{\max }}\left(\mu_{n} \epsilon-c\right) d G(\epsilon)\right.\right. \\
& \left.\left.\quad+\left(1-R_{a}\right) \int_{\bar{\epsilon}_{a, t+1}^{0}}^{\epsilon_{\max }}\left(\mu_{n} \epsilon-c\right) d G(\epsilon)\right\}\right] \\
& \quad k \sum_{a=0}^{T-1}\left(1-\sum_{n=1}^{N} e_{a, n, t}\right) \\
& \quad+\beta q\left(\theta_{t}\right)\left[1-\alpha\left(\theta_{t}\right)\right](1-\delta) \sum_{a=1}^{T}\left(1-\sum_{n=1}^{N} e_{a-1, n, t}\right) \sum_{n=1}^{N} \pi_{n} \lambda_{a, n, t+1}\left\{R_{a} \int_{\bar{\epsilon}_{a, n, t+1}^{0}}^{\epsilon_{\max }} d G(\epsilon)\right. \\
& \left.\quad+\left(1-R_{a}\right) \int_{\bar{\epsilon}_{a, t+1}^{0}}^{\epsilon_{\max }} d G(\epsilon)\right\},
\end{aligned}
$$

where $\alpha\left(\theta_{t}\right) \equiv-\theta_{t} q\left(\theta_{t}\right) / q^{\prime}\left(\theta_{t}\right)$.

Let us combine these equations. First, we observe from (42)-(44) that

$$
\begin{gathered}
\lambda_{a, n, t}=\mu_{n} \bar{\epsilon}_{a, n, t}, \\
\lambda_{a, n, t}=\mu_{n} \bar{\epsilon}_{a, n, t}^{0}-c, \\
\sum_{n=1}^{N} \pi_{n}\left(\mu_{n} \bar{\epsilon}_{a, t}^{0}-c\right)=\sum_{n=1}^{N} \pi_{n} \lambda_{a, n, t} .
\end{gathered}
$$

Substituting these into (40), (41), (45) and reorganizing, as well as combining them, we obtain

$$
\begin{aligned}
& \mu_{n} \bar{\epsilon}_{a, n, t}+\beta(1-\delta) \mu_{n} \int_{\bar{\epsilon}_{a+1, n, t+1}}^{\epsilon_{\max }}\left(\epsilon-\bar{\epsilon}_{a+1, n, t+1}\right) d G(\epsilon) \\
= & b-\theta_{t} k+\beta(1-\delta)\left\{\theta _ { t } q ( \theta _ { t } ) \sum _ { n = 1 } ^ { N } \pi _ { n } \left\{R_{a+1} \int_{\bar{\epsilon}_{a+1, n, t+1}^{0}}^{\epsilon_{\max }} \mu_{n}\left(\epsilon-\bar{\epsilon}_{a+1, n, t+1}^{0}\right) d G(\epsilon)\right.\right. \\
& \left.\left.+\left(1-R_{a+1}\right) \int_{\bar{\epsilon}_{a+1, t+1}^{0}}^{\epsilon_{\max }} \mu_{n}\left(\epsilon-\bar{\epsilon}_{a+1, t+1}^{0}\right) d G(\epsilon)\right\}-\mu_{n} \int_{\bar{\epsilon}_{a+1, n, t+1}}^{\epsilon_{\max }} \epsilon d G(\epsilon)\right\},
\end{aligned}
$$




$$
\begin{gathered}
\mu_{n} \bar{\epsilon}_{T, n, t}=b, \\
\mu_{n} \bar{\epsilon}_{a, n, t}^{0}=\mu_{n} \bar{\epsilon}_{a, n, t}+c \\
\left(\sum_{n=1}^{N} \pi_{n} \mu_{n}\right) \bar{\epsilon}_{a, t}^{0}=\sum_{n=1}^{N} \pi_{n} \mu_{n} \bar{\epsilon}_{a, n, t}, \\
\beta q\left(\theta_{t}\right)\left[1-\alpha\left(\theta_{t}\right)\right](1-\delta) \sum_{a=1}^{T}\left[( 1 - \sum _ { n = 1 } ^ { N } e _ { a - 1 , n , t } ) \sum _ { n = 1 } ^ { N } \pi _ { n } \left\{R_{a} \int_{\bar{\epsilon}_{a, n, t+1}^{0}}^{\epsilon_{\max }} \mu_{n}\left(\epsilon-\bar{\epsilon}_{a, n, t+1}^{0}\right) d G(\epsilon)\right.\right. \\
\left.\left.+\left(1-R_{a}\right) \int_{\bar{\epsilon}_{a, t+1}^{0}}^{\epsilon_{\max }} \mu_{n}\left(\epsilon-\bar{\epsilon}_{a, t+1}^{0}\right) d G(\epsilon)\right\}\right] \\
=k \sum_{a=0}^{T-1}\left(1-\sum_{n=1}^{N} e_{a, n, t}\right) .
\end{gathered}
$$

The last equation can also be written as

$$
\begin{aligned}
k \sum_{a=0}^{T-1} u_{a, t}= & \beta q\left(\theta_{t}\right)\left[1-\alpha\left(\theta_{t}\right)\right](1-\delta) \sum_{a=0}^{T-1} u_{a, t} \sum_{n=1}^{N} \pi_{n}\left\{R_{a+1} \int_{\bar{\epsilon}_{a+1, n, t+1}^{0}}^{\epsilon_{\max }} \mu_{n}\left(\epsilon-\bar{\epsilon}_{a+1, n, t+1}^{0}\right) d G(\epsilon)\right. \\
& \left.+\left(1-R_{a+1}\right) \int_{\bar{\epsilon}_{a+1, t+1}^{0}}^{\epsilon_{\max }} \mu_{n}\left(\epsilon-\bar{\epsilon}_{a+1, t+1}^{0}\right) d G(\epsilon)\right\} .
\end{aligned}
$$

Finally, since we consider the steady state, we may drop the time subscript and obtain (27)-(30), where (25) is used to obtain (30).

\section{Job Creation and Destruction Conditions with Policies}

The value of a new vacancy with subsidy and tax is

$$
\begin{aligned}
V= & -k+H+\beta\left\{q ( \theta ) ( 1 - \delta ) \sum _ { a = 0 } ^ { T - 1 } \gamma _ { a } \left(R_{a+1} \sum_{n=1}^{N} \pi_{n} \int_{\epsilon_{\min }}^{\epsilon_{\max }} \max \left\{J_{a+1, n}^{0}\left(\epsilon^{\prime}\right),-F_{a+1}\right\} d G\left(\epsilon^{\prime}\right)\right.\right. \\
& \left.\left.+\left(1-R_{a+1}\right) \int_{\epsilon_{\min }}^{\epsilon_{\max }} \max \left\{J_{a+1}^{0}\left(\epsilon^{\prime}\right),-F_{a+1}\right\} d G\left(\epsilon^{\prime}\right)\right)+[1-q(\theta)(1-\delta)] V\right\} .
\end{aligned}
$$

As before, $V=0$ in equilibrium. On the other hand, Nash wage bargaining implies $J_{a+1}^{0}(\epsilon)+F_{a+1}=(1-\eta) S_{a+1}^{0}(\epsilon)$ and $J_{a+1, n}^{0}(\epsilon)+F_{a+1}=(1-\eta) S_{a+1, n}^{0}(\epsilon)$, so that, given the reservation productivity property, we may write the job creation condition (46) as (33).

Noting that $S_{a, n}(\epsilon)=J_{a, n}(\epsilon)+W_{a, n}(\epsilon)-U_{a}-V+F_{a}$, the expression for surplus of 
an existing match, corresponding to (9), can be written as

$$
\begin{aligned}
S_{a, n}(\epsilon)= & \mu_{n} \epsilon-b-F_{a}+\beta(1-\delta) \int_{\bar{\epsilon}_{a+1, n}}^{\epsilon_{\max }}\left[S_{a+1, n}\left(\epsilon^{\prime}\right)-F_{a+1}\right] d G\left(\epsilon^{\prime}\right) \\
& -\beta \theta q(\theta)(1-\delta) \eta\left(R_{a+1} \sum_{n=1}^{N} \pi_{n} \int_{\bar{\epsilon}_{a+1, n}^{0}}^{\epsilon_{\max }} S_{a+1, n}^{0}\left(\epsilon^{\prime}\right) d G\left(\epsilon^{\prime}\right)\right. \\
& \left.+\left(1-R_{a+1}\right) \int_{\bar{\epsilon}_{a+1}^{0}}^{\epsilon_{\max }} S_{a+1}^{0}\left(\epsilon^{\prime}\right) d G\left(\epsilon^{\prime}\right)\right) .
\end{aligned}
$$

So from $S_{a, n}\left(\bar{\epsilon}_{a, n}\right)=0$, the threshold productivity $\bar{\epsilon}_{a, n}$ can be computed as (34). Other thresholds can be computed similarly. 
Table 1: Calibrated parameter values

\section{Exogenous Parameters}

\begin{tabular}{lcl} 
Discount factor & $\beta$ & 0.99 \\
Worker's bargaining power & $\eta$ & 0.5 \\
Unemployment elasticity of matches & $\alpha$ & 0.5 \\
Minimum match quality (normalization) & $\mu_{1}$ & 1 \\
Distribution of $\epsilon$ & $G$ & $U[0,1]$ \\
\hline
\end{tabular}

\section{Endogenous Parameters}

Scale of matching function

Cost of posting a vacancy

$\kappa \quad 0.739$

Initial training cost

$k \quad 0.4038$

Unemployment benefit

c $\quad 0.288$

Exogenous separation rate

b $\quad 0.451$

Coefficient of the probability of match quality revelation

$\delta \quad 0.0125$

Maximum match quality

$r_{a} \quad 0.001683$

$\mu_{N} \quad 2.07$ 
Figure 1: Unemployment, Separation, and Finding Rates by Age in the U.S.

(a) Unemployment Rate

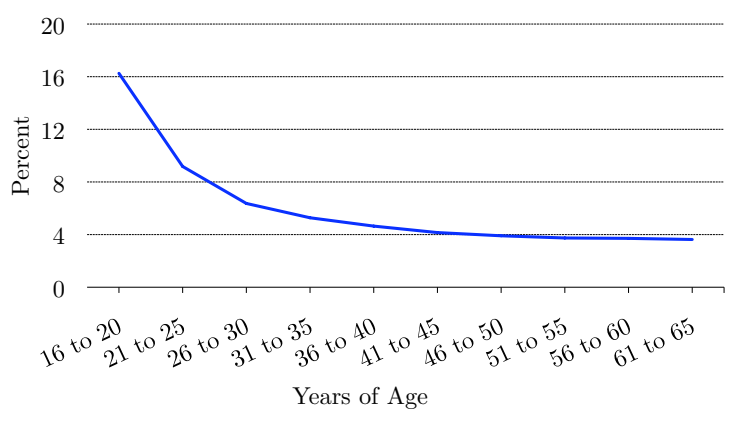

(b) Quarterly Separation Rate

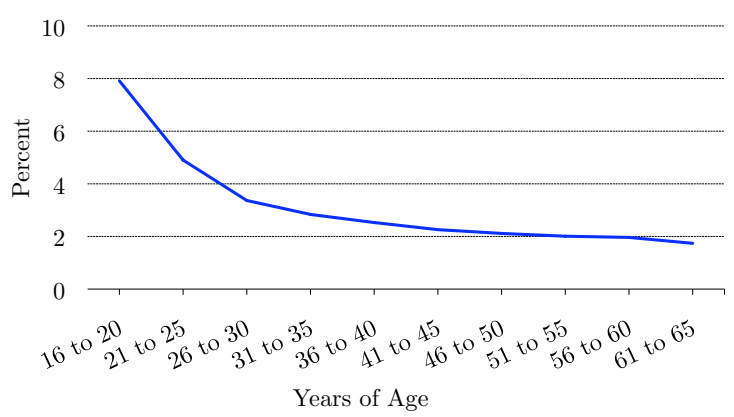

(c) Quarterly Finding Rate

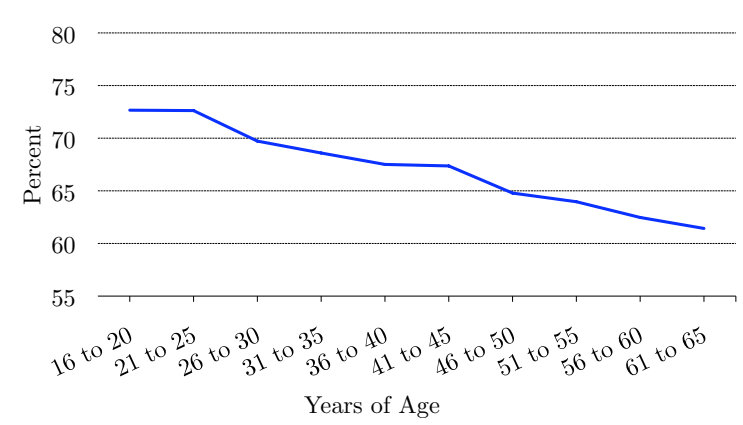


Figure 2: Unemployment, Separation, and Finding Rates in the Data and the Model

(a) Unemployment Rate

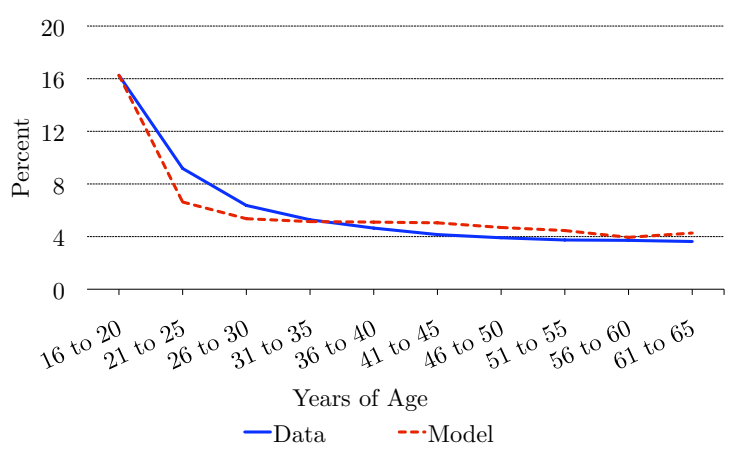

(b) Quarterly Separation Rate

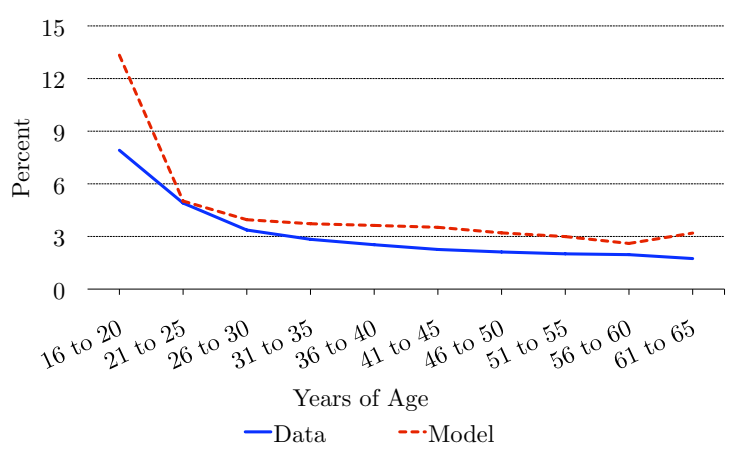

(c) Quarterly Finding Rate

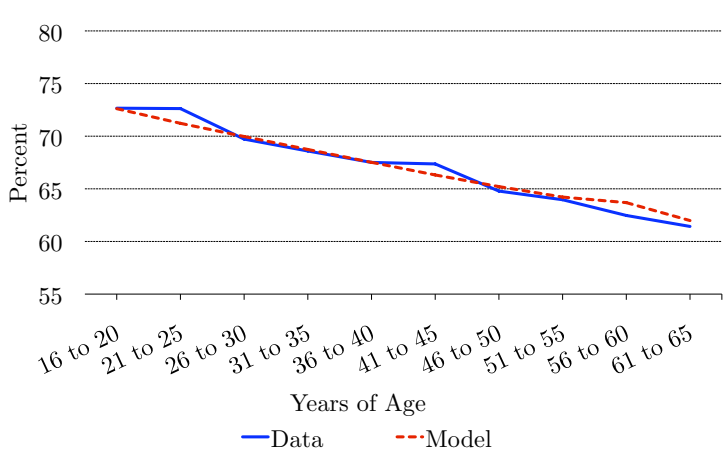


Figure 3: Social Planner's and Decentralized Equilibrium Allocations

(a) Unemployment Rate

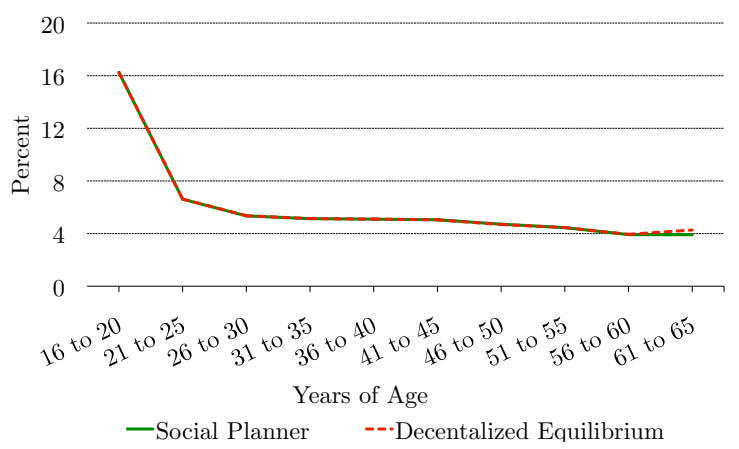

(b) Quarterly Separation Rate

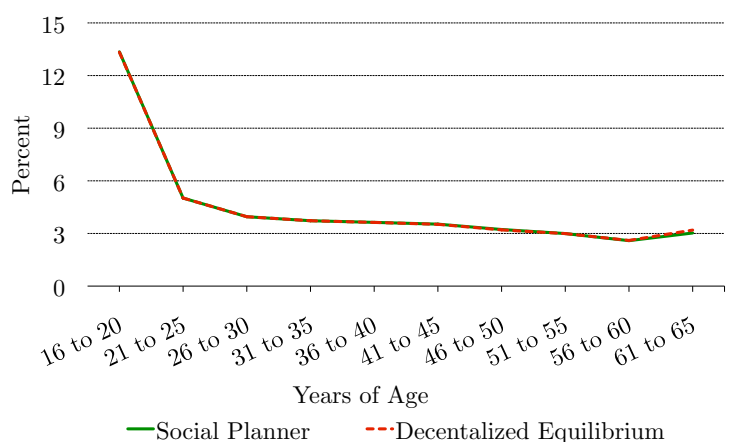

(c) Quarterly Finding Rate

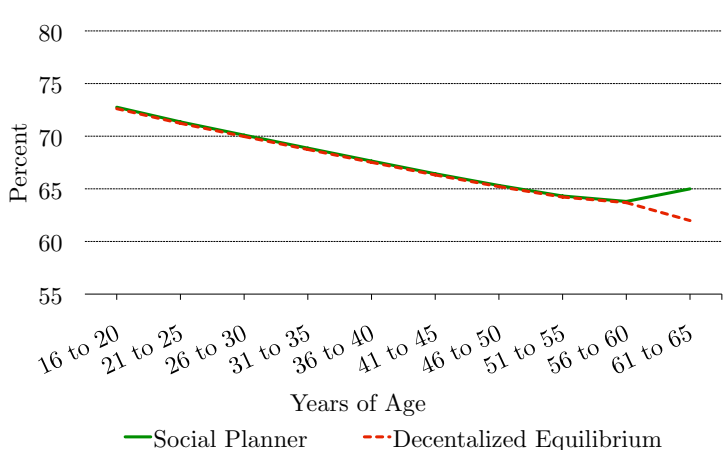


Figure 4: Optimal Firing Tax by Age

(a) Firing Tax

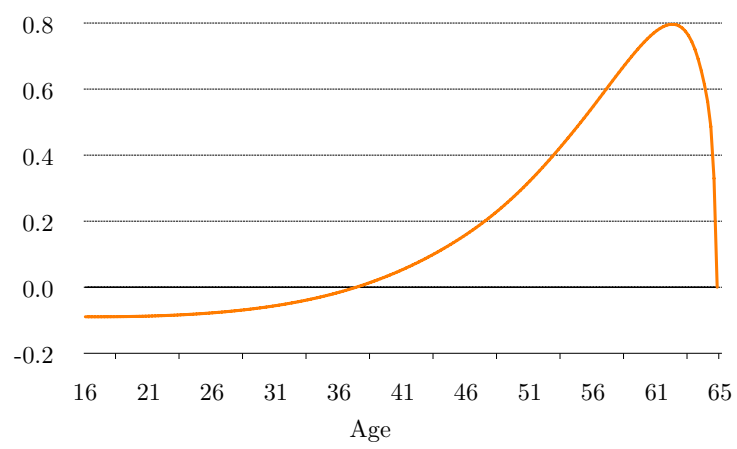

(b) Effective Firing Tax: $F_{a}-\beta(1-\delta) F_{a+1}$

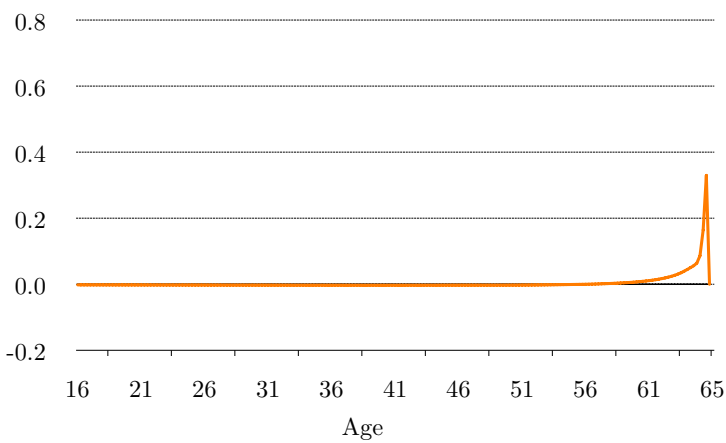

